\title{
Design of an Improved Type Rotary Inductive Coupling Structure for Rotatable Contactless Power Transfer System
}

\author{
Jia-You Lee ${ }^{a}$, Hsin-Ming Chen and Li-Yu Huang \\ Department of Electrical Engineering, National Cheng Kung University, Tainan City, Taiwan
}

\begin{abstract}
This paper is aimed at analyzing the rotary inductive coupling structure of contactless rotary transformer. The main feature of the proposed rotatable contactless power transfer system is which winding is coaxial-interlayered for improving the magnetic coupling capability. There is no ferrite core used in the secondary-side of the rotary inductive coupling structure, this helps to ease the exerted force that is stress by the secondary-side on spindle. In order to verify the feasibility of the proposed contactless power transfer system for rotary applications, an inductive powered rotary machinery and the control system have been integrated. The experimental results show that the maximum power transfer efficiency of the proposed rotary inductive coupling structure is about $94.8 \%$. The maximum output power received in the load end is $1030 \mathrm{~W}$ with transmission efficiency of $88 \%$.
\end{abstract}

\section{Introduction}

The need of resources from earth is growing day to day. For the construction of all industrial civilization and the exploitation of resources such as mineral mining, oil drilling, aerospace engineering, and wind power, they all need the industrial machinery with rotary motion. In most cases, the action of those rotating machinery is rotated in single direction and do not have the back rotation function. The power supplied to a rotating shaft is usually by mechanical slip-ring assemblies, which is always followed the risk of tear and wear of assemblies caused by the inherent high friction between the metallic conductors. If the power supplied to a rotating shaft by general wire assemblies, it may cause the entanglement of power supply wire. According to this reason, there is required to find a way that the power supply wire will not entangle with rotary part of machinery while operating.

The solution for supplying power to rotary machinery can be divided into the contact and contactless ways, respectively. The common solution of the contact way is to supply power by mechanical slip-ring assemblies, which is always led to the wear of assemblies. It will increase the cost of equipment maintenance and add the probability of replacing consumables [1]. In addition, the temperature of slip-ring joints may rise in the process of rotary status, in turns, it may cause the conductive joints burning. The flying sparks are also generated by surface friction, increasing the risk of special working environment such as the refineries, wet and conductive environment, high temperature treatment, and clean room. Therefore, it is necessary to develop the contactless power transfer method for rotary machinery with high reliability to reduce the risk and disaster while operating under hard environment. The contactless power supply techniques can be divided into two ways: the inductive power transfer techniques [2-3] and the capacitive power transfer techniques [4-5]. Figure 1 shows the illustrations of these two different contactless power transfer ways for rotary machinery.

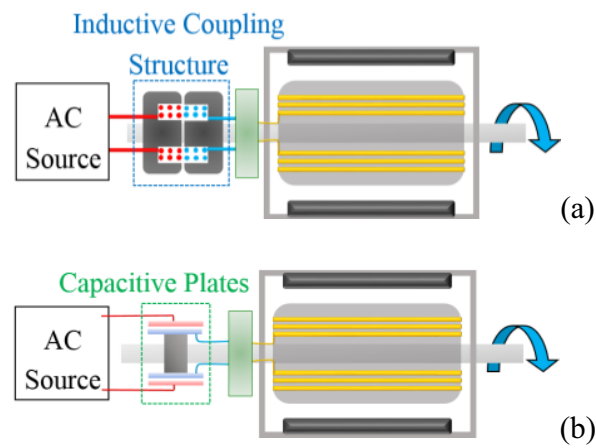

(a)

(b)

Figure 1. Contactless ways for rotary machinery. (a) Inductive. (b) Capacitive.

The inductive power supply technique is used to transfer power by alternating magnetic field between the different coils. It has the advantage of low maintenance requirement and high power transmission capacity, but it still requires installing coil windings and the magnetic material on the rotating shaft which adds additional stress on shaft equipment. The stability of power transmission may also be affected by the rotational speed that is depending on the design of the coupling structure. In the other hand, the capacitive power supply technique is used to transfer power by alternating electric field between two conductive plates. It depends on the amount of electric charge that accumulated between two plates, but it still

a Corresponding author: leejy@mail.ncku.edu.tw 
has a bottleneck to manufacture the plate capacitor with enough capacitance to apply high power. For the high power requirements in such industrial application nowadays, the contactless inductive power transmission technique is utilized to develop and implement an improved type rotary inductive coupling structure for rotatable contactless power transfer system that is not sensitive to the rotational speed and can transfer power to the rotary load steadily.

\section{Contactless power transfer system}

The general application of contactless power transmission technology in the overall system architecture is shown in Figure 2. The whole system can be divided into the primary-side power supply part, the inductive coupling structure, and the secondary-side pickup part, respectively. By applying a high frequency exciting circuit, the dc power source can be converted into a high frequency alternating power source that supplies a high frequency current into the primary-side coil and generates a high frequency magnetic field by the resonant compensation circuit. Then the magnetic field is captured by the secondary-side inductive coil and transferred to a high frequency inductive current. The inductive current will be compensated by resonant circuit and rectified as a dc power source for supplying the power to output load.

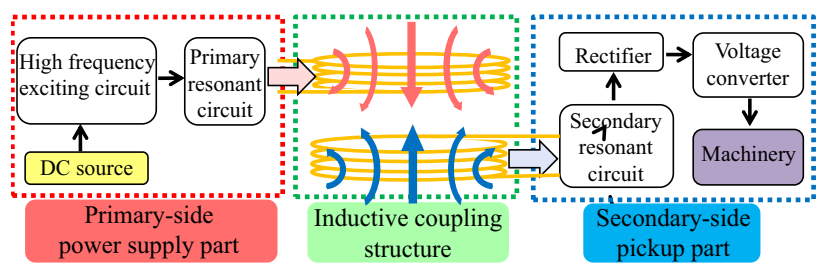

Figure 2. Block diagram of a contactless power transfer system.

The difference between the inductive coupling structure and the general transformer is that the air-gap within the coils of the primary-side and the secondaryside. In general, the air-gap of an inductive coupling structure is larger than a transformer, which means the inductive coupling capability is weaker than the transformer. Besides, the larger air-gap causes a larger leakage inductance, thus reduces not only the coupling effect but also the transmission capacity of power. In view of this, a contactless inductive power transfer system may add resonant capacitors in the circuit of both sides for compensation to enhance the power transfer capability [6]. While the system circuit is operated at the resonant frequency, the inductive reactance and the capacitive reactance formed by the inductive coils of two sides and compensative capacitors will be offset by each other, it makes the system impedance of circuit purely resistive.

Due to the inductive power transfer characteristic, it is not sensitive with the variation of output load under the following two compensation topologies of Figure 3. In this paper, these two resonant topologies are taken into analysis and design for the proposed system. First, the inductive coils of both sides are in series with resonant capacitors as shown in Figure 3(a), which is called as S-S resonant topology. Figure 3(b) shows the S-P resonant topology, its inductive coil of the secondary-side is paralleled with resonant capacitor. In Figure 3, the subscript symbol $P$ represents the primary-side, $S$ represents the secondary-side. $L_{P}$ and $L_{S}$ are the selfinductances of the primary-side and the secondary-side, respectively. Besides, $r_{P}$ and $r_{S}$ are the coil resistances of the primary-side and the secondary-side, respectively. $i_{P}$ and $i_{S}$ are the currents of the primary-side and the secondary-side, respectively. $R_{L}$ is the output load. The impedance of the secondary-side is different which depends on the compensation topology of secondary-side as illustrated in Figure 4.

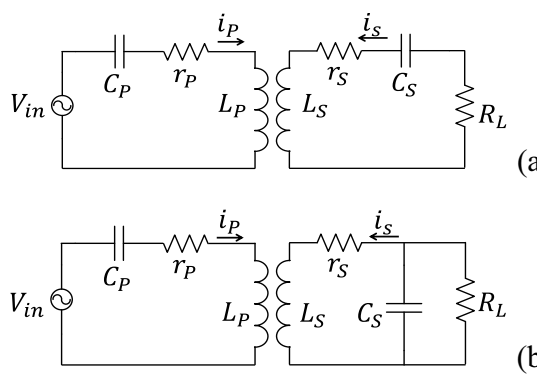

Figure 3. Two types of resonant topologies. (a) S-S. (b) S-P.

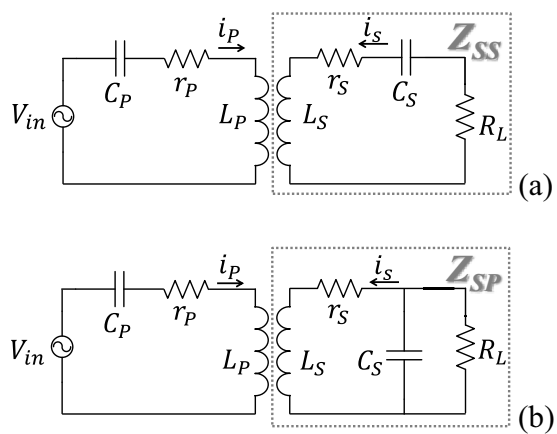

Figure 4. Equivalent impedance of the secondary-side circuit. (a) S-S. (b) S-P.

The equivalent impedance of the secondary-side while the resonant topology is under S-S and S-P, respectively, can be expressed as:

$$
\begin{gathered}
Z_{S S}=j \omega L_{S}+r_{S}+\frac{1}{j \omega C_{S}}+R_{L} \\
Z_{S P}=j \omega L_{S}+r_{S}+\frac{1}{j \omega C_{S}+1 / R_{L}}
\end{gathered}
$$

When the frequency of system is operated at the resonant frequency $\omega_{0}=1 / \sqrt{L_{S} C_{S}}$, the equivalent impedance of the secondary-side will be based on the relationship between the frequency and the mutual inductance $M$ reflected to the primary-side circuit, where $Z_{X}$ can be expressed as $Z_{S S}$ or $Z_{S P}$. The reflection impedance $Z_{r}$ is given as:

$$
Z_{r}=\frac{\omega^{2} M^{2}}{Z_{X}}
$$


The effective impedance reflected on the terminal of primary-side circuit from secondary-side is as shown in Table 1 .As the system frequency is operated at the resonant frequency $\omega_{o}$ of the secondary-side and satisfied its resonant condition, the equivalent impedance reflected back to the primary side can be derived as shown in Table 2. According to the different resonant topologies, the overall power transfer efficiency of the system could be calculated [7]. The overall power transmission efficiency of the whole system can be defined as $\eta=\eta_{P} \cdot \eta_{S}$, where $\eta_{P}$ is the efficiency between the input and the reflected impedance from secondary-side, $\eta_{S}$ is efficiency between the reflected impedance on the secondary-side and output load. The overall power transfer efficiency can be calculated from Table 3 .

Table 1. Primary-side effective impedance reflected from the secondary-side.

\begin{tabular}{|c|c|c|}
\hline Topology & $\operatorname{Re}\left[Z_{r}\right]$ & $\operatorname{Im}\left[Z_{r}\right]$ \\
\hline S-S & $\frac{\omega^{4} M^{2} C_{S}^{2}\left(r_{s}+R_{L}\right)}{\omega^{2} C_{S}^{2}\left(r_{S}+R_{L}\right)^{2}+\left(\omega^{2} L_{S} C_{S}-1\right)^{2}}$ & $-\frac{\omega^{3} M^{2} C_{S}^{2}\left(\omega^{2} L_{S} C_{S}-1\right)}{\omega^{2} C_{S}^{2}\left(r_{S}+R_{L}\right)^{2}+\left(\omega^{2} L_{S} C_{S}-1\right)^{2}}$ \\
\hline S-P & $\frac{\omega^{2} M^{2}\left(r_{S}+R_{L}+\omega^{2} R_{L}^{2} C_{S}^{2} r_{S}\right)}{\left(r_{S}+R_{L}-\omega^{2} L_{S} C_{S} R_{L}\right)^{2}+\omega^{2}\left(r_{S} R_{L} C_{S}+L_{S}\right)^{2}}$ & $\frac{\omega^{3} M^{2}\left(R_{L}{ }^{2} C_{S}-\omega^{2} R_{L}{ }^{2} C_{S}{ }^{2} L_{S}-L_{S}\right)}{\left(r_{S}+R_{L}-\omega^{2} L_{S} C_{S} R_{L}\right)^{2}+\omega^{2}\left(r_{S} R_{L} C_{S}+L_{S}\right)^{2}}$ \\
\hline
\end{tabular}

Table 2. Effective impedance reflected from the secondary-side on resonant condition.

\begin{tabular}{|c|c|c|}
\hline Topology & $\operatorname{Re}\left[\boldsymbol{Z}_{\boldsymbol{r}}\right]$ & $\mathbf{I m}\left[\boldsymbol{Z}_{\boldsymbol{r}}\right]$ \\
\hline S-S & $\frac{\omega_{0}{ }^{2} M^{2}}{\left(r_{S}+R_{L}\right)}$ & 0 \\
\hline S-P & $\frac{M^{2}\left(r_{S}+R_{L}+\omega_{0}{ }^{2} R_{L}{ }^{2} C_{S}{ }^{2} r_{S}\right)}{L_{S} C_{S} r_{S}{ }^{2}+\left(r_{S} R_{L} C_{S}+L_{S}\right)^{2}}$ & $-\frac{\omega_{0}{ }^{3} M^{2} L_{S}}{r_{S}{ }^{2}+\omega_{0}{ }^{2}\left(r_{S} R_{L} C_{S}+L_{S}\right)^{2}}$ \\
\hline
\end{tabular}

Table 3. Overall power transfer efficiency.

\begin{tabular}{|c|c|c|}
\hline Topology & $\eta_{P}$ & $\eta_{S}$ \\
\hline S-S & $\frac{\operatorname{Re}\left[Z_{r}\right]}{r_{p}+\operatorname{Re}\left[Z_{r}\right]}$ & $\frac{R_{L}}{r_{S}+R_{L}}$ \\
\hline S-P & $\frac{\operatorname{Re}\left[Z_{r}\right]}{r_{P}+\operatorname{Re}\left[Z_{r}\right]}$ & $\frac{R_{L}}{r_{S}+R_{L}+r_{s} R_{L}{ }^{2} \omega_{0}{ }^{2} C_{S}{ }^{2}}$ \\
\hline
\end{tabular}

In design of a inductive power transfer system, the energy transfer efficiency and the electric characteristics of circuit will be decided by the resonant topology, the output power requirement, and the power transfer characteristics while output load change. Considering the input dc power source $V_{\text {in }}$ is constant, the output power $P_{o}$ received in load $R_{L}$ can be calculated by the relationship from Table 3 as follows:

$$
P_{o}=\frac{V_{i n}{ }^{2}}{\left(r_{P}+\operatorname{Re}\left[Z_{r}\right]\right)} \cdot \eta=\frac{V_{i n}{ }^{2}}{\left(r_{P}+\operatorname{Re}\left[Z_{r}\right]\right)} \cdot \eta_{P} \cdot \eta_{S}
$$

\section{Rotary inductive coupling structure}

The common inductive coupling structure used in rotary application is ferrite pot-core, which is called as rotary transformer. Based on the different coil configurations, it can be divided into adjacent and coaxial way [8]. The finite-element-method software Maxwell is used to analysis the coupling structures. Figure 5 is the simulation magnetic field strength distribution of the two rotary transformers. The magnetic field distribution of the coaxial type is more uniform due to its magnetic coupling area is wider than adjacent type. In addition, by comparing the coupling coefficient $k$ of both types, it is verified that the structure with coaxial coil has better magnetic coupling effect.

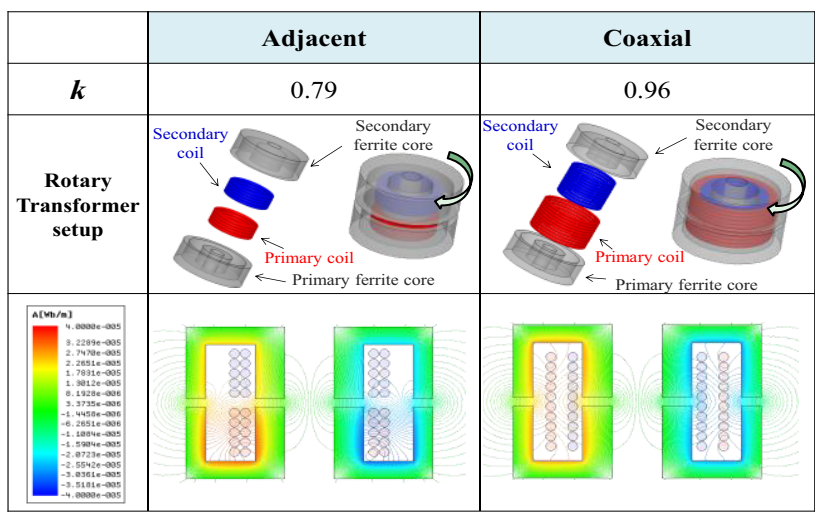

Figure 5. Magnetic field simulation of two rotary transformers.

Instead of the ferrite core fixed on the rotating part in original rotary transformer design, the ferrite core located at the primary-side is designed as an extended sharp to increase the launching distance of magnetic field. The secondary-side core is removed to ease the stress on shaft. This paper puts two kinds of design. Type I is designed as a core with almost closed sharp. Unlikely, the both windings of Type II structure are coaxial-interlayered to each other. Two designed types are simulated in Figure 6.

\begin{tabular}{|c|c|c|c|c|}
\hline & \multicolumn{2}{|c|}{ Type I } & \multicolumn{2}{|c|}{ Type II } \\
\hline 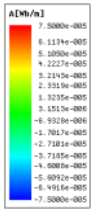 & 81 & 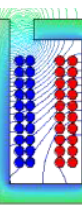 & 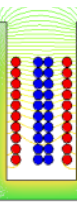 & 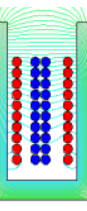 \\
\hline$k$ & \multicolumn{2}{|c|}{0.95} & \multicolumn{2}{|c|}{0.97} \\
\hline$L_{P}(\mu \mathrm{H})$ & \multicolumn{2}{|c|}{2842} & \multicolumn{2}{|c|}{1514} \\
\hline$L_{S}(\mu \mathrm{H})$ & \multicolumn{2}{|c|}{2685} & \multicolumn{2}{|c|}{1527} \\
\hline $\boldsymbol{M}(\mu \mathrm{H})$ & \multicolumn{2}{|c|}{2626} & \multicolumn{2}{|c|}{1481} \\
\hline
\end{tabular}

Figure 6. Magnetic field simulation of two coaxial design.

From the simulation results, the core of Type I is with more closed sharp, thus the reluctance is lower than Type II. Therefore, if they are with the same number of turns, the mutual inductance of Type I will be higher than Type II. On the other hand, the area which magnetic flux crosses between coils of two is larger in Type II, so that it increases the magnetic coupling capability between coils and gets the higher coupling coefficient. Consider that the Type I is nearly closed core. When designing the configuration of the coupling structure, it is difficult to integrate and reduce the freedom of system design. Hence, the actual prototype of coupling structure implemented is chosen with the Type II. Figure 7 shows the chart of specification and measurement parameters, and the measured coupling coefficient is 0.9 . The primary-side winding is divided into the inner and outer rings, both rings are with 16 turns. The secondary side is with double 
15 turns of winding, a woven Litz wire is used to reduce the equivalent series resistance of winding. The practical prototype is illustrated as Figure 8 . After the rotary machinery is installed with secondary winding, the rotary part can assembled with primary-side fixed part freely as shown in Figure 9.

\begin{tabular}{|c|c|c|c|}
\hline & \multicolumn{3}{|c|}{ Proposed Rotary Inductive Coupling Structure } \\
\hline \multirow{2}{*}{$\begin{array}{l}\text { Oblique } \\
\text { view }\end{array}$} & & $\begin{array}{c}\text { Measureing } \\
\text { Frequency }(\mathrm{kHz})\end{array}$ & 40 \\
\hline & & Litz Wire & $0.13 \mathrm{~mm} \times 80$ \\
\hline \multirow{4}{*}{$\begin{array}{l}\text { Section } \\
\text { view }\end{array}$} & \multirow[t]{4}{*}{ 14.5 mm } & $k$ & 0.9 \\
\hline & & $\boldsymbol{L}_{\boldsymbol{P}}(\mu \mathrm{H})$ & 138 \\
\hline & & $L_{S}(\mu \mathrm{H})$ & 126 \\
\hline & & $\boldsymbol{M}(\mu \mathrm{H})$ & 120 \\
\hline \multirow{2}{*}{ Coil turns } & \multirow{2}{*}{$\begin{array}{c}\text { Primary: }\left(\mathrm{P}_{1}\right)=16,\left(\mathrm{P}_{2}\right)=16 \\
\text { Secondary: }(\mathrm{S})=15\end{array}$} & $r_{P}(\Omega)$ & 0.21 \\
\hline & & $r_{S}(\Omega)$ & 0.2 \\
\hline
\end{tabular}

Figure 7. Specification and measurement parameters.
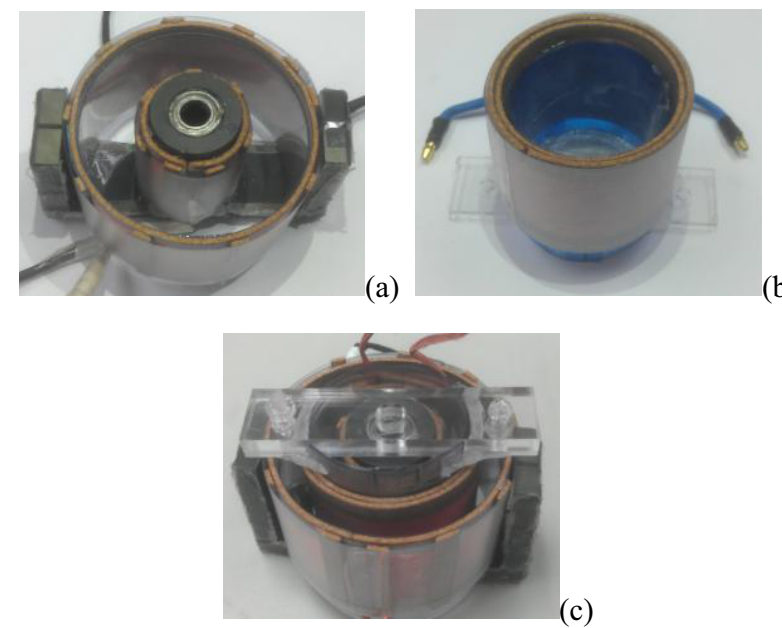

Figure 8. Practical prototype. (a) Ferrite core and coil of primary-side. (b) Secondary coil. (c) Combination of both sides.

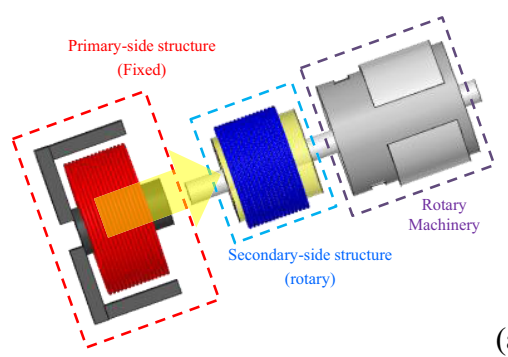

(a)

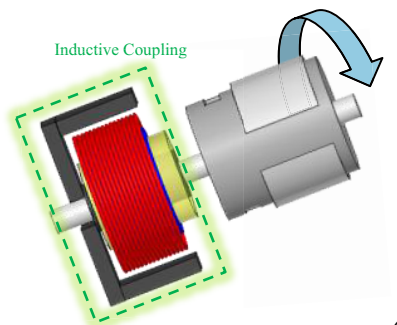

(b)

Figure 9. Assemble illustration of coupling structure and rotary machinery. (a) Before and (b) after assemble completely.
The calculated transmission power and efficiency of prototype is shown in Figure 10. Figure 11 is the calculated the output voltage and current with two different resonant topologies. From the results of calculation, in the case of adopting S-S topology, the output current is not change obviously with the variation of load. The output voltage is increased with the lager load impedance, which means that the output power is increased while the output impedance increase. While adopting S-P topology, the output voltage is changed merely with the variation of load. The output current is increased while the impedance of load is reduced, which means that the output power is increased with the decrease of output impedance. From the results of above analysis, the output load of proposed system is treated as rotary armatures. The torque of armatures is changed with the input current, thus the S-P topology is more appropriate.
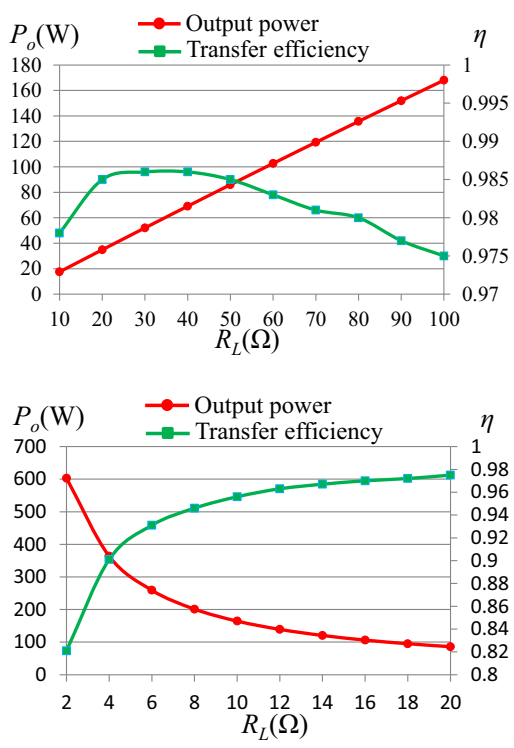

Figure 10. Calculated output power and transfer efficiency. (a) S-S. (b) S-P.

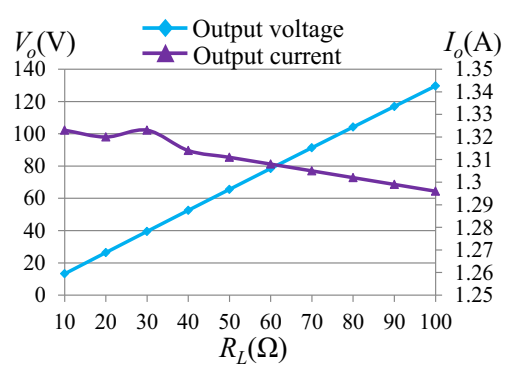

(a)

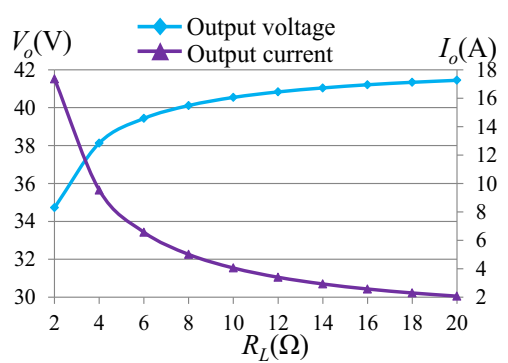

Figure 11. Calculated output voltage and current. (a) S-S. (b) S-P. 


\section{Contactless rotary machinery systems}

Figure 12 shows the block diagram of the proposed rotatable contactless power transfer system. The architecture of the control system used in the output rotary machinery is shown in Figure 13. The rotary machinery is homemade synchronous motor with threephase armatures. In design of control system, a hall sensor fixed on rotary shaft is used to determine the position of the armatures and sending signal to control the switches of three-phase bridge inverter.

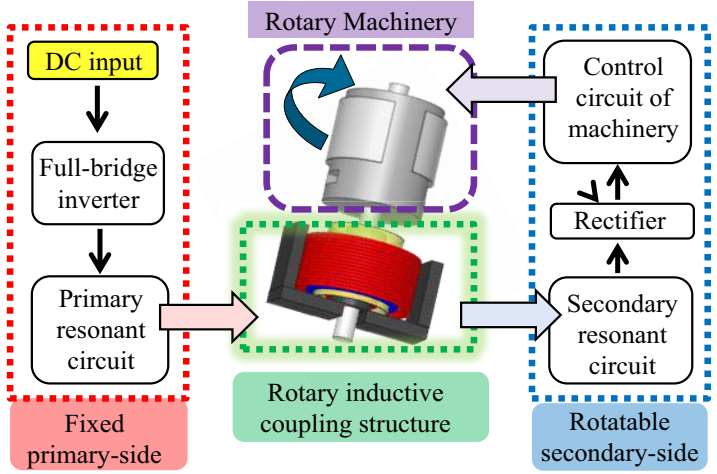

Figure 12. Proposed rotatable contactless power transfer system.

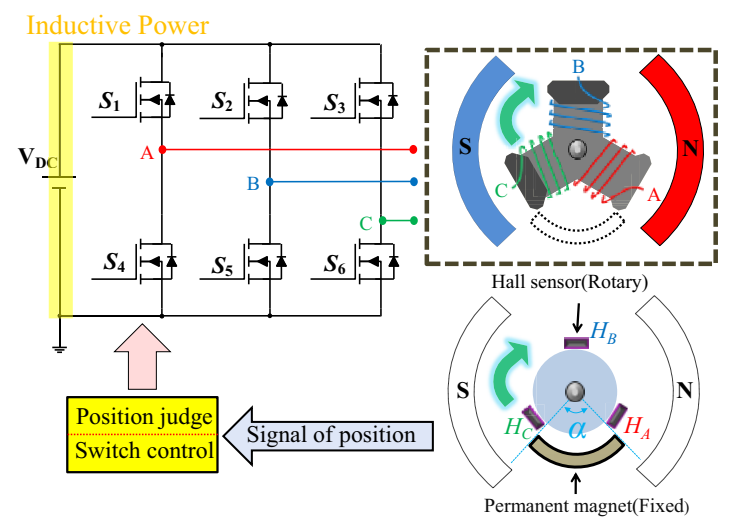

Figure 13. Architecture of the control system.

\section{Experimental results}

To verify the feasibility of the contactless power transfer system for rotary application, a platform of Figure 14 is built for experiment and measurement while the secondary-coil is rotated by a dc motor. The slip-rings are used to transfer the power to resonant, rectifier and resistance load. Thus, the voltage and current waveform on secondary-side could be measured. Figure 15 shows the practical experiment setup.

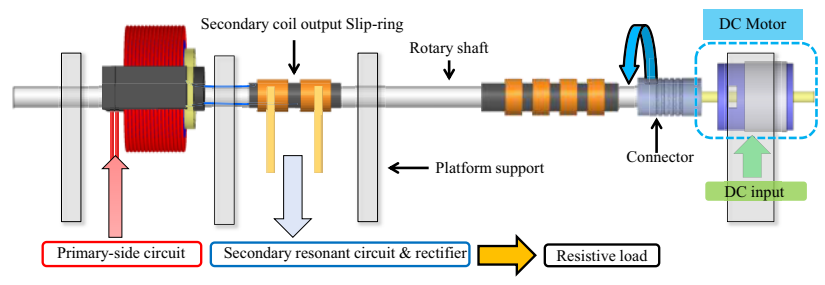

Figure 14. Platform setup for measurement.

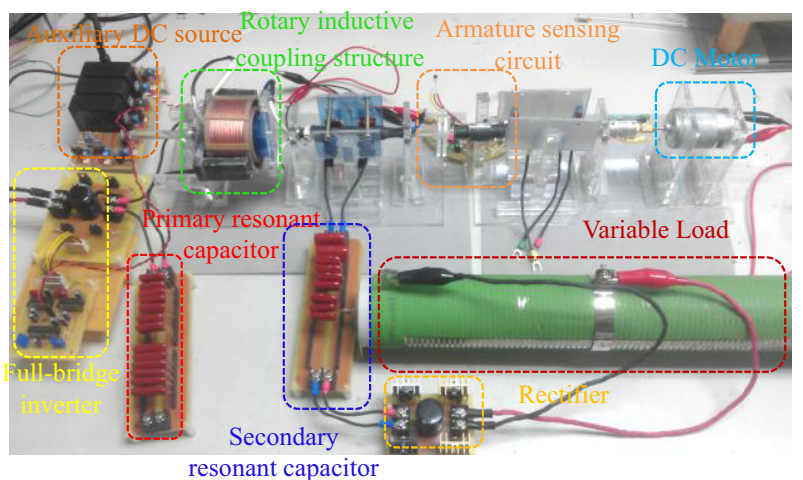

Figure 15. Practical experiment setup for measurement.

The waveforms of the primary and secondary sides while the secondary-side is under fixed and rotary status are measured. The voltage and current waveforms are not varied obviously while the secondary-side is under fixed and in rotary condition. It means that the inductive coupling effect between both coils would not be affected by the rotary motion. Therefore, the power can be transferred from the primary-side to the secondary-side stably while using the proposed rotary inductive coupling structure. The experimental results show that when the input voltage is fixed at $84 \mathrm{~V}$, the rotatable contactless power transfer system can transfer the maximum power about $1030 \mathrm{~W}$ with energy transfer efficiency of $88 \%$. In case of the output power received is less than $300 \mathrm{~W}$, the transmission efficiency is reached to $94.8 \%$. Figure 16 shows the output power and energy transfer efficiency with the variation of output load.

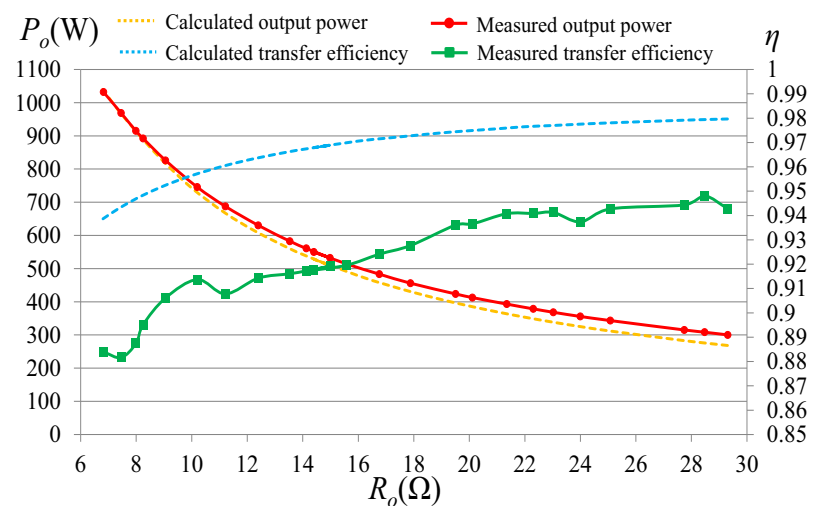

Figure 16. Output power and energy transfer efficiency.

The calculated results do not consider the switching loss at the primary-side, and the energy loss of rectifier at the secondary-side also does not included either. As the results of calculation and measurement, the calculated power transfer efficiency is higher than measured one. In the comparison of output power, the measured curve is closed to the calculated curve, but the measured one is lower than the calculated result. It can be estimated that the rectifier circuit connected with output load, the reflected impedance of output load is nonlinear, it makes the variation of reflected impedance from the output to the secondary-side circuit, thus the sending power is higher than calculated amount. In addition, while using the proposed contactless power transfer system to 
motivate the handmade rotary machinery. The secondaryside inductive coil fixed on shaft is rotated while the rotary machinery powered by the proposed system. The resonance and rectifier circuits of the secondary-side are integrated with driving circuit of machinery fixed on rotary shaft.

From the measured voltage and current waveforms on resonant circuit of both sides, it can be observed that the resonant tank has reached the resonance condition. The voltage of secondary-side resonant capacitor $v_{C S}$ is $11.7 \mathrm{~V}$, which is able to estimate that the input voltage of threephase bridge inverter is about $11 \mathrm{~V}$. Besides, the voltage period of armature are measured as $56.6 \mathrm{~ms}$. It can be estimated that the rotation speed of armature is $1071 \mathrm{rpm}$. Figure 17 shows the practical experiment setup for the measurement of voltage and current signals while the handmade rotary machinery is motivated by proposed contactless power transfer system. The practical setup situation of the driving circuit of rotary machinery fixed on shaft as shown in Figure 18.

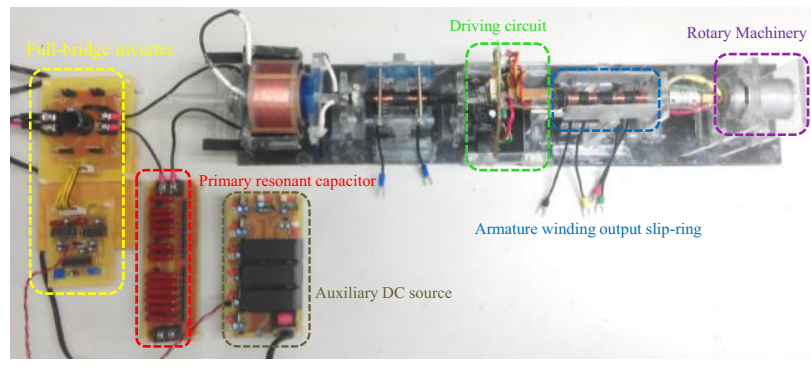

Figure 17. Practical experiment setup.
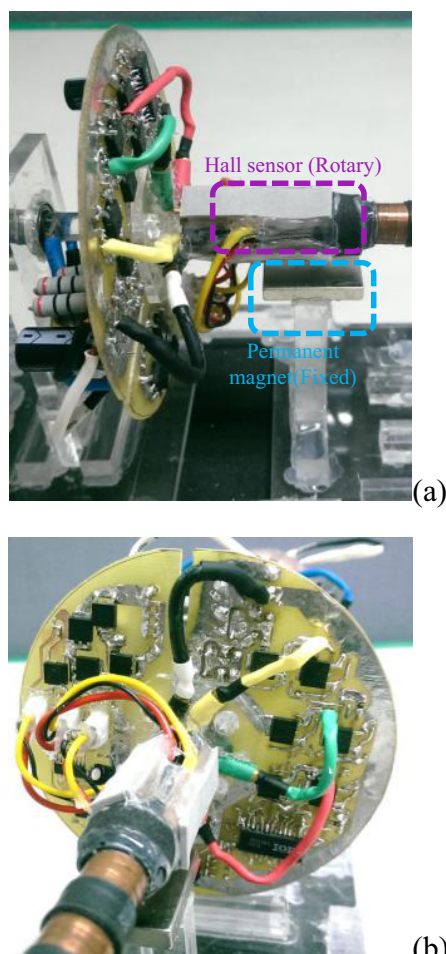

(b)

Figure 18. Practical setup of fixed driving circuit on shaft. (a) Oblique view. (b) Center view.

\section{Conclusions}

This paper is aimed at carrying out an improved design of rotary inductive coupling structure for rotatable contactless power transfer system, which can steady transfers power to the rotary load. In order to study and analysis the magnetic properties of inductive coupling structure, the finite-element-method software Maxwell is used. The main feature of the proposed rotary inductive coupling structure is that the windings are coaxialinterlayered to each other to improve the magnetic crossing area between the two coils and boost the magnetic coupling capability of structure. The ferrite core located at the primary-side is designed as an extended sharp to increase the launching distance of magnetic field. In order to verify the feasibility of the proposed system, a platform is built for experiment and measurement when the secondary-coil rotates. In addition, a synchronous motor with rotary armature and the control system has been integrated with the rotatable contactless power transfer system. In the design of control system, a hall sensor is used to determine the position of the rotary armature and send the position signal to control the switch of three-phase bridge inverter to keep armature rotate continuously.

\section{References}

1. G. Gao and W. Chen. Design challenges of wind turbine generators. IEEE Electr. Insul. Conf::146-152 (2009)

2. A. Abdolkhani and A. P. Hu. A double stator through-hole type contactless slipring for rotary wireless power transfer applications. IEEE Trans. Energy Convers., 29(2):426-434 (2014)

3. R. Trevisan and A. Costanzo. A 1-kW contactless energy transfer system based on a rotary transformer for sealing rollers. IEEE Trans. Ind. Electron., 61(11): 6337-6345 (2014)

4. D. C. Ludois, J. Reed, and K. Hanson. Capacitive power transfer for rotor field current in synchronous machines. IEEE Trans. Power Electron., 27(11): 4638-4645 (2012)

5. C. Liu, A. P. Hu, and N. K. C. Nair. Modelling and analysis of a capacitively coupled contactless power transfer system. IET Power Electron., 4(7):808-815 (2011)

6. C. S. Wang, O. H. Stielau, and G. A. Covic. Design considerations for a contactless electric vehicle battery charger. IEEE Trans. Ind. Electron., 52(5): 1308-1314 (2005)

7. X. Liu, W. M. Ng, C. K. Lee, and S. Y. Hui. Optimal operation of contactless transformers with resonance in secondary circuits. IEEE APEC:645-650 (2008)

8. K. D. Papastergiou and D. E. Macpherson. An airborne radar power supply with contactless transfer of energy-part I: rotating transformer. IEEE Trans. Ind. Electron., 54(5):2874-2884 (2007) 